Joan M. Teno

\title{
Time for change in culture
}

Received: 10 July 2012

Accepted: 13 July 2012

Published online: 1 September 2012

(C) Copyright jointly held by Springer and ESICM 2012

This editorial refers to the article available at:

doi:10.1007/s00134-012-2661-6.

J. M. Teno ( $)$

Warren Alpert School of Medicine of Brown University,

Providence, USA

e-mail: joan_teno@brown.edu

"The only way to heal is with cold steel. A chance to cut is a chance to cure"

House of God [1].

For decades, there has been a debate over the implications and causes of the striking regional variation in end-of-life care [2-6]. Barnato et al. [7] conducted a mixmethod case study that provides some important insights into the culture of decision-making processes in two intensive care units (ICUs) in the same healthcare system that differ in intensity of care among seriously ill patients in the ICU. In the ICU with the lower intensity of care, decision-making focused on the overall picture of the patient's condition, as opposed to the ICU with the higher intensity of care where the focus was on a physiological parameter as the goal of care as illustrated by this quotation: "We can't go on indefinitely. What is the end point?" with the fellow's response: "her dry weight" [7]. My characterization of the decision-making model in the high-intensity ICU is as futility-based decision-making, i.e., one that only seriously considers patient preferences when physiology cannot be supported; then you offer the patient and/or family the "choice" to withdraw or withhold life-sustaining treatment. This approach contrasts with the lower-intensity ICU approach of shared decisionmaking, where healthcare providers worked with families to arrive at decisions consistent with the prognosis and a patient's goals of care.

A case study is a qualitative research methodology that is useful in exploratory analyses to generate a hypothesis as to "why" or "how" observed patterns of behavior occur. Barnato and colleagues took a number of important steps to ensure the trustworthiness of their conclusions that include: (1) multiple theoretical perspectives on the research team, (2) triangulation of multiple sources of data, (3) investigators who coded $25 \%$ of the narratives were blinded to the ICU and achieved a high intercoder reliability score, and (4) asking those interviewed to review and assess the validity of their findings. A small concern is that they only studied two ICUs, but case studies typically involve a small number of purposefully sampled units that vary on a key characteristic such as intensity of care. More cases would help strengthen the authors' conclusions. Interestingly, this qualitative study generates more instructive conclusions about the factors explaining interhospital variability in intensity of care at the end of life than some large quantitative studies, demonstrating the value of qualitative approaches to some questions [8-10].

If we accept the validity of these findings, the unsettling question is: How do we intervene to change the ICU culture such that decision-making is based on the patient's prognosis and informed patient preferences? Such change is not just putting a sticker on the wall that reminds physicians to ask about patient preferences. I can imagine the "sticker" approach generating the question, "Do you want me to intubate your mother, Ms. Cabral?" with the underlying tone of the question being, "Do you want your mother to have oxygen, Ms. Cabral?" At the core of shared decision-making is communication that utilizes a set of strategies that attempts to understand the patient and/or family understanding of their condition, their 
hopes and goals, educates them about their prognoses and treatment options, and arrives at a treatment plan that honors realistic patient goals.

This is a complex intervention. Note that I explicitly stated a set of communication strategies. It is very important that each physician adjusts his communication strategy based on the background and needs of the patient and family with whom they are speaking, and the disease trajectory of the patient. In some cases, we should be paternalistic (e.g., in the case of an 89-year-old with advanced cancer in septic shock with the husband of 60 years unable to let go, I believe it is permissible to say that the final act of love is "letting go"), while in other circumstances our goal is to be educator and provide the best available evidence (e.g., a dean of a college who at the age of 49 years knew more about the treatment of colon cancer than many oncologists).

Can we achieve such change? Yes. In 1961, physicians stated a preference to not tell patients that they had a diagnosis of cancer. Novack et al. [11], 18 years later, reported that this attitude had changed dramatically. However, changing the culture of healthcare will take persistence and multifaceted interventions that educate, help clinicians develop the needed skills, create pathways that prompt such communication, and increase use of palliative care consults in the ICU. Change will also likely require public demands for accountability. Public reporting is an important step in ensuring that medical care is consistent with patient preferences and goals of care. The healthcare organization that does not seriously reflect on its quality of care, and examine consumer perceptions to ensure that decisions at end of life are based on informed patient values and goals, has lost the heart and soul of medicine. Yes, medical care is a business where fiscal viability is important, but the core of medical practice must be fundamental respect and caring for another human. Quality suffers when organizations focus solely on the margin or whether a bed is filled. Ultimately, the margin will suffer if the culture of the organization does not focus on quality of care.

While we are undertaking healthcare reform, whether in the USA or elsewhere, a word of caution regarding the case studies of these two ICUs should be heeded. Changing payment strategies for clinicians, hospitals, and healthcare systems will invariably result in changes in incentives and can inadvertently lead to over- or undertreatment. Our goal should be the right care for the right persons at the right location and at the right time. Incentives for clinicians and healthcare institutions should be designed, as much as possible, to create incentives for just such care.

Thirty years ago, I started my medical career reading the satirical view of internship at a prestigious Boston hospital. Since the publishing of House of God, striking changes have been made in physician training. We need to work to continue to change the culture of medical care. The best way to heal is not solely with cold steel; rather, we should listen to the patient and family and promote shared decision-making. Only then will true healing occur.

\section{References}

1. Schlem S (1979) House of God. Berkley Books, New York

2. Fisher ES, Wennberg DE, Stukel TA, Gottlieb DJ, Lucas FL, Pinder EL (2003) The implications of regional variations in Medicare spending. Part 2 : health outcomes and satisfaction with care. Ann Intern Med 138:288-298

3. Fisher ES, Wennberg DE, Stukel TA, Gottlieb DJ, Lucas FL, Pinder EL (2003) The implications of regional variations in Medicare spending. Part 1: the content, quality, and accessibility of care. Ann Intern Med 138:273-287

4. Wennberg JE, Cooper MM (1999) The Dartmouth Atlas of Health Care in the United States 1999. American Hospital Publishing
5. Bach PB (2010) A map to bad policyhospital efficiency measures in the Dartmouth Atlas. N Engl J Med 362:569-573; discussion p 574

6. Skinner J, Staiger D, Fisher ES (2010) Looking back, moving forward. N Engl J Med 362:569-574; discussion 574

7. Barnato AE, Tate JA, Rodriguez KL, Zickmund SL, Arnold RM (2011) Norms of decision making in the ICU: a case study of two academic medical centers at the extremes of end-of-life treatment intensity. Intensive Care Med. doi:10.1007/s00134-012-2661-6

8. Barnato AE, Herndon MB, Anthony DL, Gallagher PM, Skinner JS, Bynum JP, Fisher ES (2007) Are regional variations in end-of-life care intensity explained by patient preferences? A study of the US Medicare Population. Med Care 45:386-393
9. Morden NE, Chang $\mathrm{CH}$, Jacobson JO, Berke EM, Bynum JP, Murray KM, Goodman DC (2012) End-of-life care for Medicare beneficiaries with cancer is highly intensive overall and varies widely. Health Aff (Millwood) 31:786-796

10. Lin CY, Farrell MH, Lave JR, Angus DC, Barnato AE (2009) Organizational determinants of hospital end-of-life treatment intensity. Med Care 47:524-530

11. Novack DH, Plumer R, Smith RL, Ochitill H, Morrow GR, Bennett JM (1979) Changes in physicians' attitudes toward telling the cancer patient. JAMA 241:897-900 